\title{
Social-emotional Challenges Experienced by Students Who Function with Mild and Moderate Hearing Loss in Educational Settings
}

\author{
CJ Dalton \\ Queen's University
}

\begin{abstract}
Mild or moderate hearing loss (MMHL) is a communication disability that impacts speech and language development and academic performance. Students with MMHL also have threats to their social-emotional well-being and selfidentity formation, and are at risk for psychosocial deficits related to cognitive fatigue, isolation, and bullying. While the body of research on deaf and culturally Deaf students is considerable, educational literature on students with MMHL is much less extensive, especially when considering their prevalence in regular classrooms (Niskar et al., 2001). This paper investigates the social-emotional challenges of hard of hearing students using self-determination theory (Deci \& Ryan, 1985) as an organizing framework and highlights how classroom teachers can support relatedness, competence, and autonomy for students with MMHL.
\end{abstract}

The lived experience of students with mild or moderate hearing loss (MMHL) includes a communication disability that impacts speech and language development, social-emotional quality of life, and academic performance (Yoshinaga-Itano, DeConde Johnson, Carpenter, \& Stredler Brown, 2008). Students with MMHL also have threats to their social-emotional well-being and self-identity formation, and are at risk for psychosocial deficits related to cognitive fatigue, isolation, and bullying. While the body of research on academic and social-emotional needs of deaf and culturally Deaf students is considerable, educational literature investigating the needs of students with less severe hearing loss is much less extensive. It is critical that educational researchers study classroom experiences of learners with MMHL to better meet their academic and social-emotional needs.

The purpose of this paper is two-fold: (a) to gain insight into the social-emotional experiences of students with MMHL and (b) to examine these experiences through the lens of selfdetermination theory (SDT; Deci \& Ryan, 1985) and literature connected to disability identity development (e.g., Gill, 1997). Educational research on students with MMHL and socialemotional outcomes was initially targeted for this review. Given the paucity of research meeting 
these criteria, some literature on social-emotional outcomes of students with more severe hearing loss and deafness and on disability identity was also included, when it has implications for those who function with or as if they had MMHL in the classroom. An additional goal of this paper is to synthesize a broad body of literature on students with hearing loss that often appears theoretically disorganized and lacking in collective impact on educators.

Primarily, I am motivated to examine the educational and social-emotional experiences of youth with MMHL by my professional experiences as a counsellor to individuals with hearing loss and as a teacher to integrated hard of hearing students. Inspiration to investigate these issues also flows from my personal experiences as an integrated student with pre-lingual, moderatelysevere, hearing loss. There is a large body of research investigating academic performance of students with hearing loss. However, as van Gurp (2001) advised, "to provide optimal learning environments...we must examine the socio-emotional, as well as academic, impact of educational settings" (p. 54). I assert that an understanding of the social-emotional experiences of students with MMHL can be enhanced through a theoretical investigation of research examining learners with various degrees and types of hearing loss.

\section{Definition of Terms}

Hearing loss is experienced along a continuum measured by pure tone air-conduction thresholds and decibel (dB) loss. Milder degrees of hearing loss are found at one end of the spectrum, and severe and profound hearing loss, or deafness, are at the other. Mild to moderate loss can be defined as ranging from $15-30 \mathrm{~dB}$ to $30-70 \mathrm{~dB}$, depending on hearing loss types, research sources, or regulatory bodies (National Workshop on Mild and Unilateral Hearing Loss, 2005; World Health Organization, 2009; Yoshinaga-Itano et al., 2008). Individuals with more severe hearing loss are often referred to as deaf, although an individual may prefer the term hard of hearing, especially if he or she relies on listening and speech for communication. Individuals who culturally and linguistically identify as part of Deaf Culture use the capitalized term Deaf. It has been argued that students diagnosed with severe and profound hearing loss or deafness who are also cochlear implant recipients may have a functional status similar to students with MMHL when using these devices (Blamey et al., 2001; Francis \& Niparko, 2003). Generally, the term hard of hearing is used to describe individuals with hearing loss along the entire spectrum.

For the purposes of this paper, the term MMHL encompasses a broad range of students who, compared to students with more significant hearing loss or deafness, are not traditionally recipients of intensive educational interventions or support. This definition may include all those who function as if they have MMHL. Thus it refers to those diagnosed with congenital or acquired bilateral mild to moderate hearing loss or unilateral hearing loss including sensorineural, conductive, or mixed hearing loss, and those whose hearing is compromised during critical periods of academic and social development at school (e.g., progressive, fluctuating, or temporary hearing loss as a result of illness).

The term identity refers to one's sense of self and to how one is labelled in a social context (Gill, 1997). As a psychological term, identity implies an awareness of the self, self-image, or mental model described as self-esteem or self-concept (Markus \& Wurf, 1987). The term social-emotional is used to encompass a range of complex factors contributing to mental health or psychosocial status related to social interaction and intrinsic well-being (Roeser, Eccles, \& Sameroff, 2000). 


\section{Rationale for Focusing on Students with MMHL}

Educational research on children and youth with hearing loss provides neither consistent nor meaningful attention to the social-emotional experiences of those with less severe hearing loss in integrated classrooms compared to those with greater degrees of hearing loss (YoshinagaItano et al., 2008). When searching for applicable literature on hearing loss we are frequently directed to "see deaf" in the indexes. There is also a tendency by researchers to group together all hard of hearing learners along the spectrum from mild to profound, and even Deaf. Educational and psychological databases and major handbook chapters on special education, psychology of learners, and exceptional learners also primarily speak in-depth to the experiences of severe or profound, deaf, and Culturally Deaf students, while offering very little on students with MMHL; social-emotional elements or environmental contexts are also rarely addressed (Ainscow, 2007; Brinton \& Fujiki, 2002; Reynolds \& Fletcher-Janzen, 2007). Much of the expertise on students with more severe hearing loss and deafness can inform classroom teachers of integrated students with MMHL. However, these teachers may not consider seeking out a body of knowledge aimed at deaf students and may not apply it in their regular classrooms to students with less severe hearing loss (Johnson, Stein, Broadway, \& Markwalter, 1997).

Although prevalence is widely debated due to varying definitions of hearing levels and hearing loss type, to age of onset and of diagnosis, and to availability of universal screening, newborn hearing screening data indicate that 2 to 3 in 1000 infants in Canada (i.e., up to 1100 new cases annually) have congenital hearing loss, with cases of MMHL and unilateral hearing losses accounting for the majority of these cases (Canadian Working Group on Childhood Hearing, 2005). When cases of acquired hearing loss are included, researchers have reported that up to $10-15 \%$ of the student population likely has MMHL (Bess, Dodd-Murphy, \& Parker, 1998; Niskar et al., 2001; Wake et al., 2006). Review of educational research on this population is further complicated by the use of wide uncategorized ranges, by variability of amplification compliance, by cognitive development, and by intelligence level of participants (Canadian Working Group on Childhood Hearing, 2005; Tomlin \& Hebbeler, 2007; Yoshinaga-Itano et al., 2008). In a systematic audiological sampling of 1218 school children, Bess et al. (1998) found that over $5 \%$ had mild sensorineural or unilateral hearing loss. When all forms of hearing loss from mild to severe were considered in this study, the prevalence was over $11 \%$ of the sample. In a report on children with mild and unilateral hearing loss, A. Davis, Reeve, Hind, and Bamford, (2002) noted that "between five and ten percent of the clinical caseload of audiologists in the UK is mild and unilateral children" (p. 186) although caseload numbers were not provided for children with moderate or more severe hearing loss.

Reporting on a cross-sectional survey of 6166 students, aged 6 to 19 years in the United States, Niskar et al. (2001) found that $12.5 \%$ of the sample had noise induced hearing loss in one or both ears. This study ruled out children with middle ear disorders (i.e., conductive or temporary hearing loss due to illness). In a large cluster sample study of 6240 elementary students to determine prevalence of slight/mild bilateral sensorineural hearing loss, Wake et al. (2006) found that less than $1 \%$ had the targeted degree and type of hearing loss. It was also reported that $87 \%$ of the sample had normal hearing, whereas $13 \%$ did not. Also found in this sample were more cases of hearing loss in Grade 5 students than in any other grade, suggesting that a "proportion of these older children had acquired or progressive losses" (Wake et al., 2006, p. 1849) not previously detected.

With the advent of infant screening and improved amplification technology, children with profound hearing losses are often being identified earlier and having opportunities to gain a less 
severe functional status. Over the past 20 years increasing numbers of these children have acquired a cochlear implant and with these devices, many of these children have gained a $28 \mathrm{~dB}$ or greater perceptual improvement effect and are being educated orally in regular classrooms (Blamey et al., 2001; Francis \& Niparko, 2003). Accurate prevalence data for students with MMHL is lacking, but it appears that numbers could reach as high as $15 \%$ of the integrated population if all forms of MMHL are considered.

Both academic performance and social-emotional development (e.g., self-identity work, psychological needs fulfillment) can be compromised by MMHL (Marschark \& Albertini, 2004), and it is possible that students with different degrees or types of hearing loss have similar socialemotional experiences in regular classrooms. However, the mostly intelligible speech of these students "might mislead teachers and administrators to overlook the difficulties they experience with classroom participation [and]...little attention may be given to mitigating the effect of their hearing loss in the classroom" (Antia, Jones, Reed, \& Kreimeyer, 2009, p. 308). Currently, a comprehensive understanding of the social-emotional development of students with MMHL is lacking (Moeller, 2007) and many educators are not cognizant of the fact that hearing loss, regardless of severity, can have a negative impact on educational and social-emotional outcomes.

A program of research that adequately informs educational researchers and regular classroom teachers about the learning and social-emotional experiences of students with MMHL is not currently evident and it appears that professionals have not taken much notice of the larger numbers of these students in regular classrooms. What are the educational and social-emotional experiences of children and youth with a hearing loss categorized as less than severe, profound, or deaf? What are teachers' assumptions and perceptions of these students? What do students with MMHL need from their teachers to be socially-emotionally secure and confident while learning? These are the questions this paper sets out to answer.

\section{Reporting the Research}

Research addressing social-emotional experiences of students with various degrees of hearing loss has been identified for this review from educational and psychological databases. First, an overview of SDT describes three innate psychological needs (i.e., a sense of relatedness, competence, and autonomy) and different motivation regulation styles. Literature on students with hearing loss is then organized by these three psychological needs to emphasize how classroom contexts can be utilized to enhance self-determined learning and the classroom experience of students with MMHL. Some key studies pertain to more than one of the three psychological needs and are discussed in more than one section. The section on the need for a sense of competence includes a description of recent conceptions of disability identity and the unique and complex role that it can play in the development of a sense of competence. The paper ends with recommendations for educators and researchers.

\section{Self-determination Theory}

SDT (Deci \& Ryan, 1985) is a research-driven motivation theory that accounts for individual agency while making predictions about motivation and performance based on three psychological needs and self-regulation styles. SDT asserts that having a secure sense of each of relatedness, competence, and autonomy is critical to intrinsic and extrinsic motivation, social functioning, and self-determination; adverse consequences for well-being can result when these psychological needs are not met. SDT contends that motivation and self-determination can be 
enhanced by altering environmental circumstances. In the school context, teachers can enhance self-determined learning and student well-being through the implementation of practical strategies supporting these three needs in the classroom while attending to the motivational principles of SDT (Niemiec \& Ryan, 2009).

The "facilitation of more self-determined learning requires classroom conditions that allow for satisfaction of these three basic human needs" (Ryan \& Deci, 2000, p. 65). Educators, in particular, are in a position to positively influence learning environments to help students (a) achieve a sense of relatedness with other adults and with peers; (b) increase their sense of competence during the academic and social components of learning; and (c) provide opportunities to enhance students' feelings of autonomy, volition, and independence during educational endeavours. Ryan and Deci (2000) explained that a sense of relatedness is positively associated with positive school-related behaviour while reduced motivation for learning is evident when students fail to experience a secure relational base or when they view their teachers as uncaring. A sense of competence is experienced when a student feels able to deal effectively with the demands of his or her educational environment (e.g., academic tasks and social interactions). Enhanced motivation and sense of autonomy are evident when students feel able to act in harmony with their integrated selves and believe that they are a causal agent in their lives.

Ryan and Deci (2000) conducted a meta-analysis of over 30 years of motivational and behavioural research that used SDT to understand the human tendency for learning. Their purpose was to examine "the social-contextual conditions that facilitate versus forestall the natural processes of self-motivation and healthy psychological development" (Ryan \& Deci, 2000, p. 68). The authors asserted that relatedness, competence, and autonomy are innate, essential, and universal needs and that failure to satisfy these needs "contributes to alienation and illbeing... and is a principal source of human distress" (Ryan \& Deci, 2000, p. 74).

SDT differentiates between intrinsic motivation, the pursuit of an activity because it is inherently interesting or enjoyable, and extrinsic motivation, evident when one is induced to act only when behaviour leads to a separate non-inherent yet desirable outcome. Internalizing or assimilating extrinsically motivated behaviours becomes necessary "especially after early childhood when the freedom to be intrinsically motivated is increasingly curtailed by social pressures to do activities that are not interesting and to assume a variety of new responsibilities" (Ryan \& Deci, 2000, p. 71). Within extrinsic motivation, three behavioural self-regulation styles (i.e., extrinsic, introjected, and identified regulation) reflect the continuum of amotivation or unwillingness to engage in behaviours, passive compliance, or active personal commitment to the value of behaviours needed to achieve goals. Whether or not students' three psychological needs are met influences their motivation styles.

Ryan and Deci (2000) explained that students with an extrinsically regulated style of motivation (e.g., being coerced) are less likely to show interest or to expend effort on academic goals. Students with an introjected regulation style (e.g., succumbing to external pressures to enhance self-esteem) expend effort on learning tasks but also exhibit more anxiety and poor coping with failure. Those students with an identified regulation style of motivation personally identify with the value of behaviours and experience "greater enjoyment of school and more positive coping styles" (Ryan \& Deci, 2000, p. 63).

Support for these psychological needs can help maintain students' pre-existing intrinsic motivation or it can enhance their external motivation by facilitating development of more autonomous or identified self-regulation styles. Ryan and Deci (2000) concluded that the propensity for motivation requires supportive conditions to elicit and sustain development and that 
students, in particular, only begin to internalize the values and behaviours necessary for successful learning when these external supports for relatedness, competence, and autonomy are in place. For students with MMHL, the value of understanding how educators can facilitate sustainable motivation and self-determination through support of students' three psychological needs will become apparent throughout this paper.

\section{Need for Sense of Relatedness}

Fundamental to the analysis of educational experience and self-determined learning is an understanding of students' "need to feel securely connected or related to others in the school environment" (Osterman, 2000, p. 325). In an exhaustive review of nearly 20 years of literature, Osterman (2000) examined research on peer relationships, student attitudes, teacher support, and student self-esteem to assess students' need for relatedness and group inclusion. She concluded that "research consistently establishes that students receive differential treatment from teachers on the basis of characteristics such as race, gender, class, ability, and appearance" (p. 351) and "that teachers' perceptions of student engagement, as well as ability, also influence the level of support that students receive" (p. 351). Therefore, an examination of classroom contexts is critical to the investigation of social-emotional experiences of integrated students with MMHL.

Teacher-student relatedness. From a body of research highlighting the significance of caring and relationship in education, Noddings (2001) argued that a successful and caring teacher-student relationship must be directed and sustained by the educator. In 2006, Baker assessed the contribution of teacher-student relationships to student school adjustment by surveying 68 teachers on the social development and behaviour of 1310 elementary students. This study did not examine hard of hearing students specifically, but found that teacher-student relationships were moderated by student developmental vulnerabilities, learning problems, and other significant child characteristics. Like Osterman's (2000) review highlighting the significance of a caring and supportive relationship between teacher and student, Baker (2006) concluded that a positive teacher-student relationship provided children with the emotional security to fully engage in learning activities and that a protective effect was evident for developmentally vulnerable participants only when they had a close relationship with their teacher. Research with students with hearing loss is consistent with these conclusions about developmentally vulnerable students in general.

In 2002, Canadian researchers Israelite, Ower, and Goldstein (2002) conducted in-depth interviews with seven students with severe and profound hearing loss. Although participants in this study had more hearing loss than those with MMHL, they all constructed their identities in terms of what it meant to be "hard-of-hearing" instead of, and separate from, what it meant to be deaf. Participants also provided extensive detail on their social-emotional concerns, which are likely to be experienced by students with MMHL. Students' emotionally charged statements suggested that teachers "tend to stereotype and misunderstand the actions and feelings of a hard of hearing person" (Israelite et al., 2002, p. 141) and that teachers' attitudes strongly influenced their peers' attitudes at school. For students with MMHL, a strong teacher-student relationship is likely critical as well, especially when considering factors that challenge this relationship (e.g., developmental vulnerabilities, compromised communication abilities, and lack of interventions).

Two of the researchers in Israelite et al. (2002) were previously teachers to the participants in segregated settings and thus had an appreciation of how hearing loss can present challenges to students' sense of relatedness and self-determined learning. Their students were 
able to speak to "the critical role of their teachers in facilitating their development and promoting self-esteem" (Israelite et al., 2002, p. 143), suggesting a protective effect due to this close relationship. Israelite et al. advised that teachers create a "classroom environment that supports meaningful social interaction among peers [and] promote authentic student-student and teacherstudent dialogue" (p. 145). Careful attention from educators to the development of a positive caring teacher-student relationship with youth with MMHL may help facilitate their acquisition of a sense of relatedness necessary for self-determined learning and well-being at school.

Student-student relatedness. In a seminal study on students with hearing loss, J. Davis, Elfenbein, Schum, and Bentler (1986) assessed the psychoeducational status of 40 students, aged 5 to 18 years, 30 of whom had MMHL. Extensive evaluations of intelligence, language and academic status, and personality were interpreted through established norms. Each student was also interviewed and their parents were surveyed. Findings indicated that even the mildest degree of hearing loss resulted in delays of 1 to 4 years in vocabulary and parents perceived their children as "having more problems interacting with others and establishing friendships than normal" (J. Davis et al., 1986, p. 60). Significantly higher scores than the norm were also found on measures of aggression. In interviews, students reported considerable concern about social acceptance, maintaining friendships, and being teased or embarrassed (J. Davis et al., 1986). Additional interviews with 58 comparable typically hearing students found that only 9 of the 58 reported similar concerns about social acceptance. J. Davis et al. suggested that "social problems may constitute a major reflection of the effects of hearing impairment, and society's attitude towards it, on children's development" (p. 61). Findings in this study suggest that participants' psychological needs for a sense of relatedness and for a sense of competence in the social world of school may not be met.

In a study examining the vulnerability of self-concept in children with hearing loss, Loeb and Sarigiani (1986) investigated measures assessing the impact of hearing impairment on selfperceptions of 64 mainstreamed hard of hearing children, and how they differed from measures of children with visual impairments, and of those with no sensory impairment. Of the study's hard of hearing sample, $45 \%$ were determined to have MMHL while the remainder had more severe hearing loss. More often than the other two groups, hard of hearing participants reported being called names, feeling sad, having difficulties with peers, and being unpopular, whereas "such responses were never given by the visually impaired participants" (Loeb \& Sarigiani, 1986, p. 95). Teachers and mothers indicated that these students had greater difficulties in getting along with other children and with adults, compared to the other groups of children. Students with hearing loss rarely mentioned being with friends as a preferred activity and it was noted that the "peer contact that does occur is often viewed as aversive" (Loeb \& Sarigiani, 1986, p. 96). These findings suggest that a positive or adequate sense of relatedness with peers was not experienced by these hard of hearing participants. Although these two studies (i.e., J. Davis et al., 1986; Loeb \& Sarigiani, 1986) are more than 20 years old, both used mixed methods to investigate a range of social-emotional experiences and had hearing loss categories that included MMHL. Findings from these studies are also consistent with more recent research (e.g., research reviewed by Moeller, 2007).

Social comparison. In her review of historical and recent research on children with hearing loss, Moeller (2007) reported that these students "may have difficulty participating in socially oriented learning opportunities in inclusive educational settings" (p. 736). In 2001, van Gurp examined the effects of different educational settings on self-concept through a survey and 
interviews with 65 deaf secondary students. Findings suggested academic advantages for participants who attended integrated classrooms and social advantages for those attending segregated programs. van Gurp explained how children's self-concepts are affected by comparison and interactions with others and through cultural values. Harter (as cited in van Gurp, 2001) found that physical appearance and social acceptance were two critical areas of elementary and middle school student social comparison, and to a lesser extent academic and athletic competence and behavioural conduct were important. van Gurp advised that the key to analyzing the school experiences of students with hearing loss is to understand the role of social comparison in the educational context. She suggested that researchers specifically ask who students with hearing loss compare themselves to, both academically and socially.

Research on teacher-student relatedness, student-student relatedness, and social comparison (with students who have a range of hearing loss) suggests that researchers and educators require a more nuanced understanding of the multiple factors influencing both teacher and peer perceptions of students with MMHL. Integrated hard of hearing students may experience fewer social challenges and enhanced motivation if their teachers provided ongoing support for sense of relatedness by encouraging student-student participation and proactively promoted acceptance of differences amongst all members of the classroom.

\section{Need for Sense of Competence}

It is "essential to recognize that the child creates his or her environment in conjunction with family, peers, and teachers...these groups can hinder as well as facilitate self-perceptions indicative of adjustment in the hearing impaired" (Loeb \& Sarigiani, 1986, p. 98). The challenges students with MMHL face in connecting with teachers and peers could contribute to difficulties achieving a sense of competence within the social learning environment of integrated classrooms (e.g., interactive lessons, group work, and large class sizes). Punch and Hyde (2005) reported that "social self-concept of young people who are hard of hearing may be particularly vulnerable due to difficulties in the area of social participation with their peers" (p. 126). Findings from both surveys and interviews with hard of hearing youth (Kent, 2003, 2006) suggested a reluctance to self-identify as hard of hearing that may adversely impact students' development of a healthy self-concept and sense of competence with peers. Thus, in this section of the paper I integrate a description of recent understandings of disability identity and of the contribution that this complex construct may make to the development of a sense of competence in students with MMHL.

Lack of confidence and shyness. In the Loeb and Sarigiani (1986) mixed method study examining hearing, visually, and non-sensory impaired students, teachers and mothers described their children with hearing impairment as exhibiting greater shyness and less confidence at school than the other two peer groups. These students felt that a "weakness" in their own social abilities was "linked to the obstacles they face by being hearing impaired" (Loeb \& Sarigiani, 1986, p. 96). These participants also believed themselves to be unimportant, a disappointment to their families, and trouble makers at school. Such findings are especially distressing given that these students were similar to their peers in overall intellectual and school performance scores.

In the study by Israelite et al. (2002), participants reported that "being hard of hearing is like being trapped between two worlds" (p. 140); they spoke of their efforts to crack the code of "unknown rules" for communicating with typically hearing peers. These students were "caught 
in the dilemma of wanting to be included but feeling anxious and mistrustful about their encounters with hearing peers" (Israelite et al., 2002, p. 141). Likely, students with MMHL have similar concerns with confidence and require ongoing support to feel competent with the social tasks necessary for achieving learning outcomes.

In 2005, Punch and Hyde explored whether or not students with moderate to profound hearing loss avoided occupations demanding social interaction. Sixty-five integrated adolescents, one third of whom had moderate hearing loss, were surveyed on scales of loneliness; 12 of these students were also interviewed. Survey results showed no statistical differences on measures of loneliness between hard of hearing and typically hearing students. However, the interview data detailed participants' intense sense of social isolation and negative peer experiences culminating in reduced confidence in academic and social interactions. One student reported, "Well, that's why I haven't got a part-time job, because I don't really have too much confidence in working at...counters and things" (Punch \& Hyde, 2005, p. 134). The authors stressed that teachers need to be particularly sensitive to these students' intense desire for normalcy, to their reduced selfconfidence, and must actively facilitate social inclusion with peers, both inside and outside of the classroom. Of interest to educational investigators is that these students only divulged incongruent social-emotional concerns during in-depth interviews and not in survey responses.

Identity development and disability. Educators also need to be sensitive to the social construction of disability and its impact on students whose social-emotional "adjustment is inextricably linked with social context and interactions" (Best, 1999, p. 338). In Gill's (1997) report on disability identity development, she explained that there is a "common barrier to psychological wholeness that does not originate from the disability itself but in the manner in which family members, professionals, and other significant social figures frame the impact of disability for the disabled individual" (p. 43). Ryan and Deci (2000) argued that adults can support students' psychological needs when they have a realistic understanding of "the design of social environments" (p. 68) contributing to student development, performance, and well-being.

However, claiming an identity as a disabled youth is a complex undertaking. Self-identity work, as defined by Erikson (1968), is the realistic appraisal and integration of inner and outer experiences, and is an essential life task towards self-determination. Research outlines conflicting socio-cultural forces that discourage positive self-identity development by individuals with disabilities (Gill, 1997; Weinberg \& Sterritt, 1986). These implied cultural messages ensure that young people "internalize the public's fear and devaluation of disability" (Gill, 1997, p. 42) leaving them vulnerable to disillusionment and oppression. Even if a child's disability is minimal or moderate, engaging them in a process of positive disability identity integration - defined by Gill (1997) as an incorporation of all the components of the self, including the disabled self, into a whole - can have a profound impact on his or her sense of competence at school.

Many students with disabilities, regardless of severity, expend enormous effort "to prove their validity at the cost of burn out, fear of failure and, ultimately, the lack of a comfortable identity" (Gill, 1997, p. 45). These students reject an identity that includes a realistic appraisal of their disability. Disability can also manifest "in many degrees of visibility and only those with hidden impairments can play the game of passing" (Gill, 1997, p. 45). Evident in much of the research on students with hearing loss is the desire "to pass" and to emphasize "normalcy" (Kent, 2003, 2006). Students in Israelite et al. (2002) reported that "we have to be normal...talk and act like hearing students...you have to keep things private because you're just afraid what other people will think or do to you" (p. 141). Such statements hint at the effort students with MMHL 
expend to achieve a sense of competence in the social environment of integrated classrooms with their largely invisible hearing disability.

Reluctance to self-identify. Warick (1994) surveyed 290 youth with hearing loss, ages 13 to 25 , through a hard of hearing consumer group publication, to assess educational, career, social, and psychological status. Over $68 \%$ of the respondents were students and nearly $35 \%$ had MMHL while the remainder reported more severe hearing loss. Overall, these students were found to be isolated, to be reluctant to self-identify at school, and aspired to be "normal." This is a surprising finding considering that there must be some degree of acceptance of their hearing loss, given their membership and participation in the consumer group distributing the survey. One student reported trying to pay attention "to the teachers and [only] if it was necessary I would tell them I had hearing problems" (Warick, 1994, p. 255), while a second student exhibited pride in "passing as normal" when reporting that peers "couldn't believe it because it seems to them that I didn't have one [a hearing disability]" (p. 255).

Kent (2003) examined the health behaviours of 52 mainstreamed hard of hearing youth through a survey of psychosocial elements presenting barriers to well-being in school contexts. All respondents had at least a moderate hearing loss. Other than participants' higher scores on loneliness, few statistically significant academic differences were found compared to a typically hearing control group. However, 56\% of students with hearing loss - who used hearing aidsdid not self-identify as having a hearing disability when asked. Of those who did self-identify, Kent found that more were at risk physically and psychologically due to teasing and bullying compared to those who did not self-identify.

In a second study, Kent (2006) explored the perceptions of 16 adolescent hearing aid users with moderately-severe hearing loss through in-depth interviews and found that these students viewed their hearing aids as stigmatizing and "not compatible with their perceptions of what is desirable" (p. 461). Students reported that small hearing aids were preferable to more visible FM systems but that school was "fine" only when no one could see these devices. A teacher intervention advised by Kent is to normalize the use of assistive devices in the school environment. Studies by Kent $(2003,2006)$ and Warick (1994) touch on the contentious relationship between disability identity, self-concept, and sense of competence when participating in the social environment of school. Students in these studies were aware of their hearing loss but resisted self-identifying as someone whom they viewed as "less than normal."

Cultural identification and self-concept. A great deal of research explained that deaf and profoundly hard of hearing students are often part of a cultural and linguistic community with strongly held beliefs that Deaf people are not disabled (e.g., Marschark \& Albertini, 2004). Inclusion in and acceptance by a group where one is not made to feel different because of a hearing deficit are benefits of Deaf Culture membership. Without a cultural and linguistic community, youth, who are not Deaf but who have MMHL, face challenges in gaining support and acceptance, and in developing positive self-identity and self-concept. These challenges may result in a compromised sense of competence at school.

Acculturation and self-concept are also highlighted in a German web-based study of 618 hard of hearing and deaf individuals assessing development of psychosocial well-being in the context of cultural, social, and personal resources (Hintermair, 2008). Over 10\% of the respondents reported having MMHL. Findings indicated that those participants "with marginal acculturation collectively have less self-esteem and show less satisfaction with life" (Hintermair, 2008, p. 294) than those identifying with deaf or hearing cultures only. Evident for participants 
who identify with a cultural group was a heightened "significance for one's psychosocial wellbeing of having a cultural anchor" (Hintermair, 2008, p. 294). When comparing this study to a similar one in America (i.e., Maxwell-McCaw, 2001) where it was felt there is a greater willingness to accept differences, Hintermair (2008) indicated that society's acceptance of, and collective attitudes towards, the social participation of individuals with disabilities impacts overall life satisfaction. Although using a small population of youth with MMHL, Hintermair's study is one of only a few to empirically address social-emotional well-being and life satisfaction as it relates to acculturation of those with a range of hearing loss.

In a study of 115 youth with unilateral hearing loss, Bovo et al. (1988) found that $63 \%$ of respondents reported difficulty understanding speech in noise and $27 \%$ had feelings of embarrassment and inferiority. The authors reported that unilateral hearing loss is "a far from negligible handicap concerning the child's learning and relationships with classmates and teachers" (Bovo et al., 1988, p. 71). Richardson and Woodley (1999) investigated cognitive learning strategies of 382 students who had self-identified as hard of hearing on university records. Nearly 30\% were categorized as "deaf" while the remainder were labelled "hard of hearing." Respondents' scores on cognitive approaches to studying were similar to typically hearing students and unlikely to impact academic achievement. However, these students were found to have poorer previous qualifications and were older upon enrolment than students with no disabilities. Higher scores were evident on measures of motivation, maintenance of self-esteem, and fear of failure. Richardson and Woodley advised that "academic staff be appropriately trained to ensure that they encourage a positive self-concept in students with hearing loss and to not (intentionally or otherwise) promulgate negative images and stereotypes" (p. 543). These authors called on researchers to focus less on the cognitive aspects and more on the "affective consequences of hearing loss and its effects upon a student's self-concept" (Richardson \& Woodley, 1999, p. $533)$.

Explanatory models of disability. Students with MMHL may have a specific image of disability guiding their behaviour and influencing their self-concept. In a study investigating self-understanding of disability, Kinavey (2006) outlined three disability explanatory models that a student might adopt. One model, unwittingly encouraged by parents and teachers, involves overcoming society's negative view of disabled people. Yet "persistent overcoming requires persistent denial of a central part of one's self, the disabled self" (Kinavey, 2006, p. 1103) and is cognitively exhausting. A second model externalizes one's disability to limit its negative socialemotional impacts. Students may demonstrate visible discomfort when references are made to their disability and state that "as far as my disability, I just don't think about it" (Kinavey, 2006, p. 1100). With an integrated identity, however, students permit themselves to be vulnerable, to express their needs, and to act autonomously. These three models also can be informed by the self-regulation styles of motivation (i.e., extrinsic, introjected, or identified self-regulation) as outlined in SDT (Ryan \& Deci, 2000). Students with hearing loss may be extrinsically selfregulated to behave in ways that dispel society's negative view of their disability or they may have an introjected style of motivation when they ignore their disability to enhance self-esteem or if they personally identify with their disability, they may be able to act autonomously regardless of social images and attitudes.

Through an understanding of students' explanatory models of disability and selfregulation styles and through promotion of their positive self-identity development, teachers can support those with MMHL as they work towards more competent and self-determined success in classrooms. By actively altering the context of the classroom, teachers can also diminish the 
ways in which "disability is created through interactions, expectations, assumptions, remarks and ways of doing things" (Cameron, 2007, p. 508), especially when a student's disability is minimal and not necessarily visible or acknowledged by the student or his or her peers and teachers.

Teachers need to be cognizant of the influences of pervasive social attitudes towards disability to positively support hard of hearing students' sense of competence and healthy selfidentity development. Teachers must also recognize that social attitudes influence their own expectations and assessments of these youth. With awareness of the effort expended by students with MMHL to deny their disability and to appear "normal," educators can begin to appreciate how little energy is available for managing communication breakdown related to hearing loss, and for independently meeting the everyday cognitive demands of learning at school.

\section{Need for Sense of Autonomy}

Self-determined learning is more readily achieved when students' psychological need for a sense of autonomy is supported (Ryan \& Deci, 2000). However, for students with exceptionalities to take control during learning, significant adults must teach them "how to set realistic short-term and long-term goals, how to solve problems and make wise choices" (Brooks, 1999, p. 573) while providing reasonable opportunities for skill development. Unfortunately, students with MMHL who avoid self-identifying as hard of hearing, who neglect to use their assistive devices, and who resist asking for assistance from their teachers even when it is needed, may also unwittingly sabotage teachers' efforts to support their sense of autonomy.

Teachers' perceptions and classroom challenges. To support students in making realistic goals and wise choices, it is critical that teachers have a clear appreciation of the obstacles that students with MMHL face. With spoken language the preferred mode of communication, these students may have their "communication and educational needs...overlooked because of the belief that they can function easily in oral environments and have less need for support services than students who are deaf" (Antia et al., 2009, p. 294). Many educators may still have misperceptions about optimal teaching strategies and remain unaware that students with MMHL, in their attempts to independently manage their learning obstacles, are ultimately "at risk for psychoeducational and psychosocial deficits" (Tharpe, 2008, p. 12). Unfortunately, these students continue to be treated by teachers as if they have no hearing loss (Johnson et al., 1997).

In a survey of 45 teachers, $56 \%$ of whom reported current or previous professional experience with hard of hearing students, McCormick Richburg and Goldberg (2005) assessed common misperceptions about interventions for students with minimal hearing loss. Findings indicated that many teachers remain unaware of the ramifications of minimal hearing loss on educational and social-emotional needs. While examining intervention practices, the authors - an audiologist and a speech-language pathologist - believed it "disturbing to find that more teachers...strongly agreed that preferential seating alone was all that was needed for these students" (McCormick Richburg \& Goldberg, 2005, p. 13). Another study assessing the effects of degree and type of hearing loss on academic performance found that of 47 participants "some children with unilateral hearing loss as well as children with minimal hearing loss showed lower performance than children with more severe hearing loss" (Most, 2004, p. 154). It was speculated that this may be due to lack of interventions and classroom supports usually afforded to students with more severe hearing loss. 
The classroom environment itself presents challenges for hard of hearing students. In Warick (1994), over $90 \%$ of surveyed students with hearing loss reported difficulties hearing their instructors and classmates at school and claimed that new and substitute teachers were especially difficult to speech-read. These students also explained that staff changes usually meant that they had to adjust their communication strategies with little or no support from their educators. In a study on speech recognition in classrooms, Johnson et al. (1997) investigated 12 children with minimal hearing loss. The authors concluded that these students had substantial difficulties with speech comprehension and that few classrooms met acoustic criteria for their effective learning. In a report outlining challenges and opportunities for children with unilateral hearing loss, Oyler and McKay (2008) advised that teachers be educated about potential difficulties and classroom strategies and cautioned against "classrooms where poor acoustics and reverberation will affect a child's ability to understand the instruction" (p. 16).

Recommendations for classroom noise levels are usually set between $40-45 \mathrm{~dB}$ yet classrooms often produce a constant level of noise at 60-63 dB, with many reaching up to $75 \mathrm{~dB}$ or higher (Schick, Klatte, \& Meis, 2000). Studies also suggest that excessive and continuous classroom noise can lead to increased stress, inability to concentrate, and can inhibit motivation and performance outcomes for typically hearing students (Norlander, Moas, \& Archer, 2005). More adverse consequences for learning are likely for students with MMHL who rely on aural communication in noisy classrooms.

Misinformed teachers, excessive noise, changes to teaching staff, and expecting students with MMHL to carry a disproportionate amount of responsibility for successful communication impact their learning and social-emotional experience. It is also unlikely that these youth-who have a communication disability-have the know-how, self-confidence, or even the undivided attention of their teachers to accomplish the daunting task of educating their educators about hearing loss, especially in front of their peers. It is unrealistic to believe that these students are capable of autonomous learning to reach their full potential, without ongoing support.

Assistive devices. Assistive amplification devices, such as hearing aids and FM systems, present complex issues for students' sense of autonomy and ultimately for their teachers. The benefit of amplification is undeniable, yet it is unreasonable for teachers to rely on these devices to manage all of the risks to independent learning that students with MMHL face. Even when these devices are prescribed, studies by Bess et al. (1998) and Kent (2006) have indicated that they are rarely used or inconsistently used. In a study of 66 students with unilateral and mild hearing loss, over 50\% with unilateral hearing loss and $44 \%$ with mild hearing loss who were prescribed amplification devices reported "never" using them (A. Davis et al., 2002).

The complexity associated with the use of these devices is evident when one hard of hearing student reported, "I use a FM at school. I don't really feel comfortable wearing it in classes...it does help me a lot. But I don't like using it around the other students" (Punch \& Hyde, 2005, p. 132). Due to social anxiety, students seem to be willing to forego the benefits of amplification, preferring instead to suffer adverse learning consequences. Considering students' reduced speech comprehension and increased cognitive fatigue when negotiating their school day without the benefit of their assistive devices, educators can begin to appreciate how compliance issues can impede self-determined learning.

Student well-being. Not surprisingly, students' overall well-being is negatively impacted by MMHL. In a study of 1218 Grade 3, 6, and 9 students to determine prevalence of minimal sensorineural hearing loss, educational performance, and functional status, Bess et al. 
(1998) found that "even the mildest forms of permanent hearing impairment can be associated with poorer functional health status" (p. 349). Wake, Hughes, Collins, and Poulakis (2004) investigated the health-related quality of life of 89 eight-year-olds with congenital hearing loss; nearly 54\% had MMHL. Surveyed parents indicated that hearing loss had a significant impact and "unexpectedly, milder hearing losses tended to be related to worse scores" (p. 415). These findings confirm the need for further investigation into the social-emotional experiences of this population. Unfortunately, no specific educational variables impacting health related quality of life were investigated in this study (e.g., itinerant, speech-language or teacher interventions, integrated or segregated classrooms). Yet, the conclusion was that "what may appear to clinicians to be a relatively mild condition can still pose significant threats to well-being for the children" (Wake et al., 2004, p. 416).

In a review of literature on unilateral and minimal bilateral hearing loss in children, Tharpe (2008) concluded that students with "relatively mild hearing loss may exert more energy than their normal-hearing peers to listen in a classroom setting, thus leaving them with less energy and capacity for processing what they hear, taking notes, and other activities" (p. 12). Cognitive fatigue may also manifest in behaviour issues (e.g., distraction, inattentiveness, or disinterest) which can be easily misinterpreted by teachers (Oyler \& McKay, 2008) and preclude participation in extracurricular school activities that ultimately diminishes the educational experience for students with hearing loss (Israelite et al., 2002). Consequently, "these young people may experience feelings of deficiency, rather than efficacy" at school (Punch \& Hyde, 2005, p. 126).

McCain and Antia (2005) examined communication participation, academic achievement, and social behaviour of 18 non-disabled hearing students in a co-enrolled classroom with 10 students described as deaf and hard of hearing (DHH), 7 of whom had MMHL. From student and teacher reported scales, the authors found that these DHH students were not significantly different from their hearing peers in communication participation or social behaviour, whereas some delay in their academic achievement was evident. Unique features of a co-enrolled classroom include, among other things, the use of a collaborative two teacher team that consists of a general education teacher and a teacher of DHH who is fluent in sign language, the use of both English and sign-language by teachers and students, and a 2:1 ratio of typical hearing to $\mathrm{DHH}$ students. Considering these teacher-student and hearing-DHH student ratios, ample opportunities exist for intimate teacher knowledge of and immediate response to students' learning and psychological needs and for development of positive and normalized social interaction between classmates. Such findings reinforce the argument that when teaching strategies and classroom are designed primarily to provide supportive contexts for students with MMHL, a sense of being autonomous and successful in their learning environment can result.

Student variables such as compliance with assistive devices, quality of life and wellbeing, cognitive fatigue, and an apparent desire for independence, even when help is needed, contribute to the inconsistent messages being sent to classroom teachers who are attempting to support a sense of autonomy for students with MMHL. Yet, teachers can provide enabling contexts through tailored learning activities and careful consideration of the design of the learning environment to support student self-efficacy. With the receipt of ongoing sensitive support, students with MMHL should be better able to set realistic learning goals, solve communication problems, and make positive and informed choices, which is autonomy enabling.

It is clear that regardless of severity of hearing loss, students' psychological needs as defined by SDT are often adversely affected at school. Students with MMHL, in particular, may 
face greater challenges for satisfying these basic psychological needs than their typically hearing or more severely hard of hearing peers due to the invisibility and variability of their disability, their need to be seen as typically hearing students rather than identifying with those with more severe hearing loss, and the apparent lack of educational supports and interventions provided in their regular classrooms. Students' desire for relatedness with their teachers and peers, for successful inclusion in the social arena of their schools, and for control over their learning environment may intensify their resistance to indentifying as different from their typical hearing peers and may undermine self-determined learning. Teachers' ability to effectively gauge the learning potential of these students can be enhanced, however, by being attuned to degree of disability integration and motivation styles. With social-emotional needs in mind, teachers can also tailor positive learning opportunities and set realistic expectations for students with MMHL.

\section{Recommendations}

From this research, a number of recommendations can be drawn for educators and researchers. Classroom teachers can proactively facilitate learning outcomes for students with MMHL by attending to not only academic and communication needs, but to social-emotional needs as well. First and foremost, a strong and caring teacher-student relationship can set a foundation for enhanced motivation for self-determined learning. Students with MMHL must have a strong sense of belonging and connection to those in their educational environment. To achieve a better sense of competence in participating in the classroom with peers, students require support for developing confidence and should be encouraged to believe that their hearing loss can be positively integrated with self-identity. To provide a sense of autonomy, teachers must consider that students' ability to learn with MMHL is undermined by noise, cognitive fatigue, lack of compliance with assistive devices, and a need to have some control over their communication environment. As Ryan and Deci (2000) explained, for enhanced development of self-determination teachers must proactively control "the design of social environments that optimize peoples' development, performance and well-being" (p. 68).

Given the increasing numbers of students experiencing MMHL in integrated classrooms, implications for educational researchers include turning their attention to inclusive and effective evidence-based practices for use by teachers of these exceptional students. Given that students with hearing loss give contradictory reports on surveys and during face-to-face interviews (e.g., Kent, 2006; Punch \& Hyde, 2005), existing research can be enhanced by qualitative studies that target key informant perspectives on the social-emotional variables that impact the educational experience of students with MMHL. Such research can also investigate the influence of complex social-emotional concerns not previously considered such as disability integration, identity development, and motivational styles. Research on students with MMHL must also address their intense desire to be seen as "normal" and how this may override help-seeking behaviour in classrooms. Future investigations of students with MMHL will also benefit from an assessment of social-emotional effects due to an absence of successful identification with a distinct cultural group (e.g., Deaf or hearing culture). Finally, an important goal is to assess whether students with MMHL can benefit from similar or different supports and interventions currently afforded to students with more significant degrees of hearing loss. Continued use of SDT as an educational analytical tool will build on the insights gained from this paper, enhance empirical investigation of the experiences of students with MMHL, and pragmatically inform classroom teachers about the social-emotional needs of this population of exceptional students. 


\section{References}

Ainscow, M. (2007). From special education to effective schools for all: A review of progress so far. In L. Florian (Ed.), The SAGE handbook of special education (pp. 146-159). Thousand Oaks, CA: Sage Publications.

Antia, S., Jones, P., Reed, S., \& Kreimeyer, K. (2009). Academic status and progress of deaf and hard-ofhearing students in general education classrooms. Journal of Deaf Studies and Deaf Education, 14, 293-311. doi:10.1093/deafed/enp009

Baker, J. A. (2006). Contributions of teacher-child relationships to positive school adjustment during elementary school. Journal of School Psychology, 44, 211-229. doi:10.1016/j.jsp.2006.02.002

Bess, F., Dodd-Murphy, J., \& Parker, R. A. (1998). Children with minimal sensorineural hearing loss: Prevalence, educational performance, and functional status. Ear and Hearing, 19(5), 339-354. Retrieved from http://www.ncbi.nlm.nih.gov/pubmed/9796643

Best, S. J. (1999). Psychosocial correlates of physical and health disabilities. In V. L. Schwean \& D. H. Saklofske (Eds.), Handbook of psychosocial characteristics of exceptional children (pp. 336-343). New York, NY: Kluwer Academic/Plenum.

Blamey, P., Sarant, J., Paatsch, L., Barry, J., Bow, C., Wales, R.,...Rattigan, K. (2001). Relationships among speech perception, production, language, hearing loss, and age in children with impaired hearing. Journal of Speech, Language, and Hearing Research, 44, 264-285. doi:10.1044/1092-4388(2001/022)

Bovo, R., Martini, A., Agnoletto, M., Beghi, A., Carmignoto, D., Milani, M., \& Sangaglia, A. (1988). Auditory and academic performance of children with unilateral hearing loss. Scandinavian Audiology. Supplement, 30, 71-74.

Brinton, B., \& Fujiki, M. (2002). Social development in children with specific language impairment and profound hearing loss. In P. Smith \& C. Hart (Eds.), The Blackwell handbook of childhood social development (pp. 588-603). Malden, MA: Blackwell.

Brooks, R. (1999). Fostering resilience. In V. L. Schwean \& D. H. Saklofske (Eds.), Handbook of psychosocial characteristics of exceptional children (pp. 472-585). New York, NY: Kluwer Academic/Plenum.

Cameron, C. (2007). Whose problem? Disability narratives and available identities. Community Development Journal, 42(4), 501-511. doi:10.1093/cdj/bsm040

Canadian Working Group on Childhood Hearing. (2005). Early hearing and communication development: Canadian Working Group on Childhood Hearing $(\mathrm{CWGCH})$ resource document. Ottawa, ON: Minister of Public Works and Government Services Canada. Retrieved from http://www.phac-aspc.gc.ca /publicat/eh-dp/index-eng.php

Davis, A., Reeve, K., Hind, S., \& Bamford, J. (2002). Children with mild and unilateral hearing impairment. In R. Seewald \& J. Gravel (Eds.), A sound foundation through early amplification: Proceedings of the Second International Conference (pp. 179-186). Phonak, AG: Stafa Switzerland. Retrieved from http://www.phonak.co.uk/print.com_2001proceedings_chapter14.pdf

Davis, J., Elfenbein, J., Schum, R., \& Bentler, R. (1986). Effects of mild and moderate hearing impairments on language, educational, and psychosocial behavior of children. Journal of Speech \& Hearing Disorders, 51(1), 53-62.

Deci, E., \& Ryan, R. (1985). Intrinsic motivation and self-determination in human behavior. New York, NY: Plenum.

Erikson, E. (1968). Identity, youth and crisis. New York, NY: W.W. Norton.

Francis, H., \& Niparko, J. (2003). Cochlear implantation update. Pediatric Clinics of North America, 50, 341361. doi:10.1016/S0031-3955(03)00034-8

Gill, C. (1997). Four types of integration in disability identity development. Journal of Vocational Rehabilitation, 9, 39-46. doi:10.1016/S1052-2263(97)00020-2

Hintermair, M. (2008). Self-esteem and satisfaction with life of deaf and hard-of-hearing people - a resourceoriented approach to identity work. Journal of Deaf Studies and Deaf Education, 13(2), 278-300. doi:10.1093/deafed/enm054

Israelite, N., Ower, J., \& Goldstein, G. (2002). Hard-of-hearing adolescents and identity construction: Influences of school experiences, peers, and teachers. Journal of Deaf Studies and Deaf Education, 7(2), 134-148. doi:10.1093/deafed/7.2.134 
Johnson, C., Stein, R., Broadway, A., \& Markwalter, T. (1997). "Minimal” high-frequency hearing loss and school-age children: Speech recognition in a classroom. Language, Speech, and Hearing Services in Schools, 28, 77-85. Retrieved from http://web.ebscohost.com.proxy.queensu.ca

Kent, B. (2003). Identity issues for hard-of-hearing adolescents aged 11, 13 and 15 in mainstream settings. Journal of Deaf Studies and Deaf Education, 8(3), 315-324. doi:10.1093/deafed/eng017

Kent, B. (2006). They only see it when the sun shines in my ears: Exploring perceptions of adolescent hearing aid users. Journal of Deaf Studies and Deaf Education, 11(4), 461-476. doi: 10.1093/deafed/enj044

Kinavey, C. (2006). Explanatory models of self-understanding in adolescents born with spina bifida. Qualitative Health Research, 16(8), 1091-1107. doi:10.1177/1049732306292092

Loeb, R., \& Sarigiani, P. (1986). The impact of hearing impairment on self-perceptions of children. The Volta Review, 88(2), 89-100.

Markus, H., \& Wurf, E. (1987). The dynamic self-concept: A social psychosocial perspective. Annual Review of Psychology, 38, 299-337. doi:10.1146/annurev.ps.38.020187.001503

Marschark, M., \& Albertini J. (2004). Deafness and hearing loss. In W. E. Craighead \& C. B. Nemeroff (Eds.), The concise Corsini encyclopedia of psychology and behavioral science (3rd ed., pp. 312-315). Hoboken, NJ: John Wiley \& Sons.

Maxwell-McCaw, D. (2001). Acculturation and psychological well-being in Deaf and hard of hearing people. Unpublished doctoral dissertation. Washington, DC: The George Washington University.

McCain, K., \& Antia, S. (2005). Academic and social status of hearing, deaf, and hard of hearing students participating in a co-enrolled classroom. Communication Disorders Quarterly, 27, 20-32. doi:10.1177/15257401050270010201

McCormick Richburg, C., \& Goldberg, L. R. (2005). Teachers' perceptions about minimal hearing loss: A role for educational audiologists. Communication Disorders Quarterly, 27, 4-19. doi:10.1177/15257401050270010301

Moeller, M. (2007). Current state of knowledge: Psychosocial development in children with hearing impairment. Ear \& Hearing, 28, 729-739. doi:10.1097/AUD.0b013e318157f07f

Most, T. (2004). The effects of degree and type of hearing loss on children's performance in class. Deafness and Education International, 6, 154-166. doi:10.1002/dei.177

National Workshop on Mild and Unilateral Hearing Loss: Workshop Proceedings. (2005, July). Breckenridge, CO: Centers for Disease Control and Prevention. Retrieved from http://www.cdc.gov/ncbddd/ehdi /documents/unilateralh1/Mild_Uni_2005\%20Workshop_Proceedings.pdf

Niemiec, C., \& Ryan, R. (2009). Autonomy, competence, and relatedness in the classroom: Applying selfdetermination theory to educational practice. Theory and Research in Education, 7, 133-144. doi: $10.1177 / 1477878509104318$

Niskar, A. S., Kieszak, Holmes, S., Esteban, E., Rubin, R., \& Brody, D. (2001). Estimated prevalence of noiseinduced hearing threshold shifts among children 6 to 19 years of age: The Third National Health and Nutrition Examination Survey, 1988-1994 (US). Pediatrics, 108(14), 40-43. Retrieved from http://pediatrics.aappublications.org/cgi/content/abstract/108/1/40

Noddings, N. (2001). The caring teacher. In V. Richardson (Ed.), Handbook of research on teaching (4th ed., pp. 99-105). Washington, DC: American Educational Research Association.

Norlander, T., Moas, L., \& Archer, T. (2005). Noise and stress in primary and secondary school children: Noise reduction and increased concentration ability through a short but regular exercise and relaxation program. School Effectiveness and School Improvement, 16(1) 91-99. doi:10.1080/092434505000114173

Osterman, K. F. (2000). Students' need for belongingness in the school community. Review of Educational Research, 70(3), 323-367. doi:10.3102/00346543070003323

Oyler, R., \& McKay, S. (2008). Unilateral hearing loss in children: Challenges and opportunities. ASHA Leader, 13, 12-15. Retrieved from http://www.asha.org/Publications/leader/2008/080122/ f080122b/

Punch, R., \& Hyde, M. (2005). The social participation and career decision-making of hard-of-hearing adolescents in regular classes. Deafness \& Education International, 7(3), 122-138. doi:10.1002/dei.1

Reynolds, C., \& Fletcher-Janzen. E. (Eds.). (2007). Encyclopedia of special education: A reference for the education of children, adolescents, and adults with disabilities and other exceptional individuals (3rd ed.). Hoboken, NJ: Wiley. 
Richardson, J., \& Woodley, A. (1999). Approaches to studying in people with hearing loss. British Journal of Educational Psychology, 69(4), 533-546. doi:10.1348/000709999157888

Roeser, R., Eccles, J., \& Sameroff, A. (2000). School as a context of early adolescents' academic and socialemotional development: A summary of research findings. The Elementary School Journal, 100(5), 443-471. Retrieved from http://web.ebscohost.com.proxy.queensu.ca/ehost/pdfviewer/ pdfviewer?hid=107\&sid=72aa7397-4090-4eac-b912-93f436c64939\%40sessionmgr111\&vid=3

Ryan, R., \& Deci, E. (2000). Self-determination theory and the facilitation of intrinsic motivation, social development, and well-being. American Psychologist, 55, 68-78. doi:10.1037//0003-066X.55.1.68

Schick, A., Klatte, M., \& Meis, M. (2000). Noise stress in classrooms. In A. Schick, M. Meis, \& C. Reckhardt (Eds.), Contributions to psychological acoustics: Results of the 8th Oldenburg Symposium on Psychological Acoustics (pp. 533-569). Oldenburg: BIS. Retrieved from http://www.hoerzentrumoldenburg.de/web/public_files/dokumente/schick_classroom.pdf

Tharpe, A. M. (2008). Unilateral and mild bilateral hearing loss in children: Past and current perspectives. Trends in Amplification, 12, 7-15. doi:10.1177/1084713807304668

Tomlin, B., \& Hebbeler, K. (2007). Current state of knowledge: Outcomes research in children with mild to severe hearing impairment-approaches and methodological considerations. Ear \& Hearing, 28, 715728. doi:10.1097/AUD.0b013e318157f093

van Gurp, S. (2001). Self-concept of deaf secondary school students in different educational settings. Journal of Deaf Studies and Deaf Education, 6(1), 54-69.

Wake, M., Hughes, E., Collins, C., \& Poulakis, Z. (2004). Parent-reported health-related quality of life in children with congenital hearing loss: A population study. Ambulatory Pediatrics, 4(5), 411-417. http://www.sciencedirect.com.proxy.queensu.ca/science/journal/15301567

Wake, M., Tobin, S., Cone-Wesson, B., Dahl, H., Gillam, L., McCormick, L.,..Williams, J. (2006). Slight/mild sensorineural hearing loss in children. Pediatrics, 118, 1842-1851. doi: $10.1542 /$ peds.2005-3168

Warick, R. (1994). A profile of Canadian hard-of-hearing youth. Journal of Speech-Language Pathology and Audiology, 18(4), 253-259.

Weinberg, N., \& Sterritt, M. (1986). Disability and identity: A study of identity patterns in adolescents with hearing impairments. Rehabilitation Psychology, 31(2), 95-102. doi:10.1037/h0091538

World Health Organization. (2009). Grades of hearing impairment. Retrieved from http://www.who.int/pbd /deafness/hearing_impairment_grades/en/index.html

Yoshinaga-Itano, C., DeConde Johnson, C., Carpenter, K., \& Stredler Brown, A. (2008). Outcomes of children with mild bilateral hearing loss and unilateral hearing loss. Seminars in Hearing, 29, 196-211. doi:10.1055/s-2008-1075826

\section{Author's Note}

Correspondence concerning this article should be addressed to CJ Dalton, 511 Union Street, Faculty of Education, Duncan McArthur Hall, Room 106, Queen's University, Kingston, ON K7M 5R7. E-mail: cj.dalton@queensu.ca 